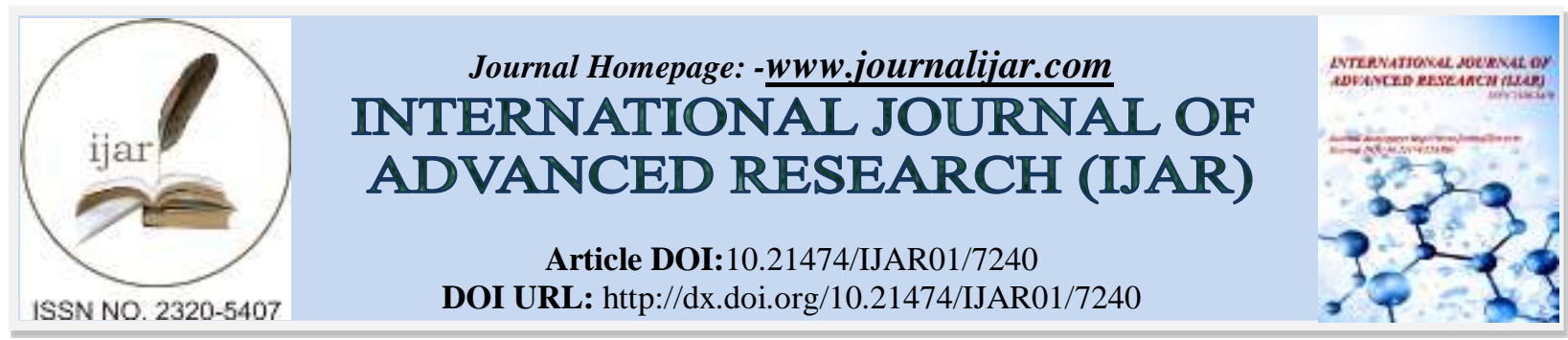

RESEARCH ARTICLE

\title{
PRELIMINARY ANALYSIS OF THE HEMAGGLUTINATING ACTIVITY OF SEED EXTRACTS OF THE AMARANTH GENUS.
}

\section{Leonardo N. R. Dandeu ${ }^{1}$, Rodolfo Repollo ${ }^{2}$, Jorge A. Oyhenart ${ }^{3}$ and ${ }^{*}$ Maria Rosana Ramirez ${ }^{1}$.}

1. Department of Biological Sciences, Faculty of Biochemistry and Biological Sciences.

2. UNL-CONICET, Santa Fe.

3. Faculty of Agronomy - UNL Pam.

4. INCITAP - CONICET - Faculty of Exact and Natural Sciences, UNL Pam, Santa Rosa, La Pampa.

\section{Manuscript Info}

Manuscript History

Received: 09 April 2018

Final Accepted: 11 May 2018

Published: June 2018

Keywords:-

Agglutination, Dog, Rat, Amaranthus,

Lectins, Polyphenols.

\begin{abstract}
In this study, seed extracts of cultivated Amaranthus species were tested for haemagglutinating activity. The extracts were prepared from the seeds of 7 Amaranthus cultivars and analyzed against samples from human, rat and dog erythrocytes. To detect haemoagglutination, 5\% suspensions of human blood samples of the types $\mathrm{A}, \mathrm{B}$ and $\mathrm{O}$ were prepared. The presence of polyphenols and saponins were determined in the extracts, yielding positive results for polyphenolics compounds. In order to characterize the proteins present in the amaranth extracts, the protein gel electrophoresis technique was applied. All extracts analyzed showed protein activity, and similar protein profile. The extracts reacted strongly with red blood cells (RBCs) from human ABO blood groups. It also reacted with rat and dog RBCs. The hemagglutinating activity was exhibited by the all extracts and the precipitated lectins from all species tested, however, hemolytic activity was not observed. The results obtained from the Amaranthus extracts indicate that it is non-specific for glycosylated antigens of the $\mathrm{ABO}$ system. The findings provide essential information for their use as potential hemoclasification reagents in the immunohematology laboratory.

Copy Right, IJAR, 2018,. All rights reserved.
\end{abstract}

\section{Introduction:-}

Plants belonging to the genus Amaranthus (Family Amaranthaceae) are commonly used for the stimulation of the immune system. Traditionally, the population has used this specie against infections for its antibacterial, antiviral and antifungal action. ${ }^{1}$ Some of the active compounds of Amaranthus have been identified, such as proteins, saponins, phytosterols, flavonoids and polyphenols. The proportions of these components differ depending on the part of the plant analyzed. Genetic and environmental factors, such as UV light exposure and harvesting method, also play an important role in chemical composition. ${ }^{2}$ In addition, the genus Amaranthus has been reported to be a lectin-rich genus among the family Amaranthaceae. ${ }^{3}$ These lectins extracts have been found to be non-specific, that is, they agglutinate a variety of human and animal erythrocytes including rabbit, rat, guinea-pig, sheep, goat and chicken. ${ }^{4}$ The Amaranthus seeds lectins have also been informed as strong lymphoagglutinins. ${ }^{4,5,6}$ Other investigators have indicated that lectin extract, from Amaranthus caudatus permit the identification of the proliferative pool of cells in the colon and provides information regarding the oligosaccharide structures associated 
with this behavior. ${ }^{6,7}$ In particular, it allows the identification of areas of inappropriate proliferation, such as those found in familial adenomatous polyposis (autosomal dominant inherited condition). Gonor et al. (2006), showed the influence of a diet supplemented with amaranth oil on dynamic of antioxidant and immune status in patients with ischemic heart disease and hyper-lipoproteidemia. ${ }^{8}$ They observed that, the antiatherosclerotic diet produces antioxidant effects and positive changes of the immune state. Based on the above, the objective of this work was to investigate the potential agglutinating activity of seeds of different varieties of Amaranthus, cultivated in the Semiarid Pampean region (Argentina). For practical purposes, this work sought to give an approximation to the possibility of extending the use of these extracts rich in lectins in the blood bank, using simple and inexpensive extraction methods.

\section{Materials and Methods:}

Seed extract: Amaranthus seeds was kindly provided by "INTA-Anguil.", Santa Rosa, La Pampa, Argentina. The seeds come from the following crops: Amaranthus cruentus var. Morelos, Amaranthus cruentus cv. Candil, Amaranthus cruentus var. Tarasca mexican morphotype, Amaranthus cruentus var. Amont, Amaranthus hypochondriacus 280 FK-FH1, Amaranthus caudatus L. CAC 48A, Amaranthus pumilus RAFIN K 340. ${ }^{9,10}$

Phytochemical prospection tests: For this analysis, a preliminary phytochemical study of fruit extracts was made; the purpose was to find the main secondary metabolites associated with biological activities (flavonoids, tannins, polyphenols). Phytochemical prospecting tests were performed with the hexane, ethanolic and hydroalcoholic extracts (Ciccarelli, Argentina). ${ }^{11,12}$

Table 1:-Number assigned to each extract studied. Experimental:

\begin{tabular}{|c|c|}
\hline & Specimens of amaranth plants analyzed. \\
\hline Extract number & Variety/specie and origin \\
\hline$E x 1$ & Amaranthus cruentus var. Morelos (Mexico) \\
\hline$E x 2$ & Amaranthus cruentus cv. Candil (Río Cuarto, Argentina) \\
\hline$E x 3$ & Amaranthus cruentus var. Tarasca mexican morphotype (Mexico) \\
\hline$E x 4$ & Amaranthus cruentus var. Amont (USA) \\
\hline$E x 5$ & Amaranthus hypochondriacus 280 FK-FH1 (Hungary) \\
\hline$E x 6$ & Amaranthus caudatus L. CAC 48A (Peru) \\
\hline$E x 7$ & Amaranthus pumilus RAFIN K 340 (Czech Republic) \\
\hline
\end{tabular}

The preparation of the extracts was carried out, with some modifications, according to the method, proposed in the Technical Manual of the American Association of Blood Banks [AABB], for the use of lectins. ${ }^{13}$ Extract were prepared as 10 percent suspensions of triturated seeds in phosphate buffered saline (PBS), pH 7.0 (Delva, Argentina). After 12 hours incubation at room temperature, the suspensions were centrifuged and the supernatant fluid was removed for testing. In addition, fractions were prepared from the same extract by means of precipitation with ammonium sulfate. Extracts were stored at $-20^{\circ} \mathrm{C}$.

\section{Electrophoresis:}

To evaluate the purity of the purified material and estimate its molar mass, the aqueous extract, the protein precipitate and the pool of active fractions were run electrophoretically on SDS-PAGE gels, following the technique described by Laemmli (1970). ${ }^{14,15}$ The subunit molecular mass was estimated by electrophoresis on polyacrylamide gel in SDS with or without the addition; using a Comassie blue solution to dye the bands. When estimating, by electrophoresis, the molar mass of the active proteins of the species under study, 5 bands were obtained, and one band, whose run coincides with the molar mass of $20 \mathrm{kDa}$ (Results not shown).

\section{Erythrocyte agglutination assays:}

For the preparation of erythrocyte suspensions at $4 \% \mathrm{v} / \mathrm{v}$, whole blood was used, collected with anticoagulant EDTA, from: adult ambulatory patients, without pathologies diagnosed (American Association of Blood Banks, AABB), adult canines without pathologies diagnosed, coming from veterinary biochemical laboratory, and Wistar male rats (220-250 g). For the typing of $\mathrm{ABO} \mathrm{RhD}$ erythrocytes, antibody reagents were used monoclonal: anti-A; anti-B and Anti-D (Rho). Suspensions of reactive erythrocytes were used, at 2-4\%, as panels for detection of irregular antibodies (Reagent Red Blood Cells for detection of unexpected antibodies, Panoscreen ${ }^{\circledR}$ ); in order to have erythrocytes of known phenotype for the following membrane antigens: D, C, E, c, e, M, N, S, s, P1, Lea, Le 
$\mathrm{K}, \mathrm{k}, \mathrm{Fy}_{\mathrm{a}}, \mathrm{Fy}_{\mathrm{b}}, \mathrm{Jk}_{\mathrm{a}}, \mathrm{Jk}_{\mathrm{b}}$. Table 2 shows the antigens present (+) and absent (0) in each of the vials used. Each of the seven extracts was faced with both vials.

Table 2:-Antigens of the panels.

\begin{tabular}{|c|c|c|c|c|c|c|c|c|c|c|c|c|c|c|c|c|c|c|}
\hline \multicolumn{19}{|c|}{ Irregular antibodies panels } \\
\hline $\mathbf{V}$ & \multicolumn{5}{|c|}{$\mathbf{R h}-\mathbf{H r}$} & \multicolumn{4}{|c|}{$\mathbf{M N}$} & $\mathbf{P}$ & \multicolumn{2}{|c|}{ Lewis } & \multicolumn{2}{|c|}{ Kell } & \multicolumn{2}{|c|}{ Duffy } & \multicolumn{2}{|c|}{ Kidd } \\
\hline Dono & $\mathrm{D}$ & $\mathrm{C}$ & $\mathrm{c}$ & $\mathrm{E}$ & $\mathrm{e}$ & $\mathrm{M}$ & $\mathrm{n}$ & $\mathrm{S}$ & $\mathrm{s}$ & $\mathrm{P}_{1}$ & $\mathrm{Le}^{\mathrm{i}}$ & $\mathrm{Le}^{\mathrm{t}}$ & $\mathrm{K}$ & $\mathrm{k}$ & $\mathrm{Fy}$ & $\mathrm{Fy}$ & $\mathrm{Jk}^{\mathrm{a}}$ & $\mathrm{Jk}^{\mathrm{b}}$ \\
\hline $\mathbf{I}$ & + & + & 0 & 0 & + & + & + & 0 & + & 0 & + & 0 & + & + & + & + & + & + \\
\hline II & + & 0 & + & + & 0 & + & 0 & + & 0 & + & 0 & + & 0 & + & 0 & + & + & 0 \\
\hline
\end{tabular}

In a second instance, a stability test was carried out during 10 days, to evaluate if the biological properties of the extract remained intact during that period of time. Seeds extract were tested against several red cells samples including: 1- group A, group B and group 0 cells. 2- for Panoscreen®. 3- Tests were also performed with canine and rat cells. Experiments were performed after protocol approval by the Institutional Ethics Committee and were carried out according to the current guidelines for laboratory animal care and ethical guidelines for investigations of experimental pain in conscious animals. Each animal was used only once and, the number of animals used was the minimum necessary for demonstrating the consistent effects of the treatments.

\section{Classification protocol:-}

The agglutination activity was evaluated by means of classic immunohematological techniques. For this, 5\% suspensions of human blood samples classified as blood groups A, B and O were prepared, which were reacted with the saline extracts; the precipitates of lectins and with the fractions obtained with solvents of different polarities. These reactions were allowed to incubate for 15 seconds and, after the necessary time had elapsed, the degree of agglutination was observed with the naked eye and through a microscope, in different periods of time (2-30 min), the interpretation of the results was performed using the following indices by crosses: $(-)$ non-agglutination, $(+)$ weak agglutination, (++) medium agglutination, (+++) strong agglutination, (++++) full agglutination. Hemolysis was determined visually based on the physical transformations of viscosity and color.

\section{Results and Discussion:-}

The results obtained, after facing each one of the extracts with the samples of erythrocytes A, B, O, D; canine erythrocytes and rodent erythrocytes are detailed in Table 3. The extracts agglutinated all types of erythrocytes employed in the bioassay. Although the agglutination intensities were intense (3+ to 4+), marked differences were observed between the three types of selected erythrocytes, being particularly weak the agglutinations corresponding to the vials. A number of authors have provided evidence that lectins have specificity for a carbohydrate, which is present in the membrane of erythrocytes. They bind reversibly to this molecule, without altering the covalent structure of the recognized glycosidic ligands. ${ }^{4,5}$ Based on these findings, it is possible to suggest some specificity of the extracts towards ligands present in the erythrocyte membrane. In agreement with these results Hardman et al. (1983), reported the agglutination of human ABO erythrocytes by three Amaranthus lectins (A. retroflexus, A. caudatus, A. tricolor). In the case of Amaranthus caudatus has been shown to react with human ABO, rat, sheep, guinea-pig, rabbit, and goat of red blood cells. ${ }^{4}$ In this study all Amaranth extracts exhibited very similar results; this fact reinforces the hypothesis of chemically defined compounds as responsible for the hemagglutinating activity. This correlation is corroborated by the inhibitory effect observed with the saline extracts as well as the ethanolic fraction. In this regards, the literature shows that polyphenols are capable of producing hemagglutination. ${ }^{16}$ 


\begin{tabular}{|c|c|}
\hline \multicolumn{2}{|c|}{ Intensity comparison between blood types } \\
\hline Blood type & Intensity \\
\hline A & $21+$ \\
\hline B & $24+$ \\
\hline D & $17+$ \\
\hline O & $21+$ \\
\hline Canine & $22+$ \\
\hline Rat & $17+$ \\
\hline Vial I & $17+$ \\
\hline Vial II & $13+$ \\
\hline Erythrocyte pool control & $0+$ \\
\hline
\end{tabular}

Table 3:-taken for aggluttination activity was as follows: $++++($ very strong $)>+++($ strong $)>++($ moderate $)>$ + (light) $>-$ (no activity).

Therefore, we hypothesize that the haemagglutinating effect of ethanolic extracts (rich in polyphenolics compounds) might be, at least in part, caused by its phytocompounds. However the polyphenols, are considered as pseudoagglutinating agents, since they do not cause haemagglutination but an agglomeration, by approaching the blood cells. This correlated with observations by Rogers and Wend Loveless (1991). ${ }^{16}$ Under the conditions of this study, hemolytic activity was not observed in the blood groups tested; these observations may be related to the absence of saponins in the extracts. Similar results were described by other researchers, who reported only haemagglutinating activity for Amaranth extracts. ${ }^{4,5}$

In conclusion, these results demonstrated that extracts obtained from different cultivars of Amaranth, grown in the Semi-arid Region have strong haemagglutinating properties. These data suggested that, the effect of the extracts may be caused by the presence of lectins and other phytocompounds, in combination. Although further studies, are needed to confirm this hypothesis. To the best of our knowledge, this is the first report to demonstrate that Amaranthus pumilus extract possess haemagglutinating property.

\section{Acknowledgements:-}

This work is supported by grants from the CONICET (PIP 11220150100833), Argentina. Special thanks to Prof. Nilda Reinaudi for her collaboration and, the National Institute of Agricultural Technology (INTA-Anguil-Santa Rosa, LP). 


\section{References:-}

1. Hussain, Z. Amresh G., Singh, S., Rao, C., V. (2009). Anti-diarrheal and anti-ulcer effect of Amaranthus spinosus Linn. Pharm. Biol., 47, 932-939.

2. Assiak, I.E., Olufemi, B.E., Ayonde, G.O., Onigemo, M.A. (2002). Preliminary studies on the effects of Amaranthus spinosus leaf extract as an Anthelmintic in growing pigs. Trop. Veterinarian., 20, 126-129.

3. Singh, J., Kamboj, K.K., Kamboj, S.S., Sandhu, R.S., Shangary S. (1993). Affinity purification and characterization of lectins from two Amaranthus species. Plant Sci., 94: 47-53.

4. Hartman J.T., Beck M.L. (1983). Owensby, Range forb lectins. Transfusion, 23 519-522.

5. Sandhu, R.S., Arora, J.S., Chopra S.K., Kamboj, S.S. Studies on lectins from Indian plants, in: T.C. B0gHansen and E. van Driessche (Eds.), Lectins Biology, Biochemistry, Clinical Biochemistry, 5, W. de Gruyter. Berlin, 1986, 85-93.

6. Arora, J.S., Sandhu, R.S., Kamboj S.S., Chopra, S.K. (1987). Occurrence and characterization of lymphoagglutinins in Indian plants. Vox Sang., 52 134-137.

7. Kaur, N., Dhuna, V., Kamboj, S.S., Agrewala, K.S., J.N, Singh, J. (2006). A Novel Antiproliferative and Antifungal Lectin from Amaranthus viridis Linn Seeds. Protein Peptide Lett., 13, 9, 897-905.

8. Gonor, K.V., Pogozheva, A.V., Derbeneva S., et al. (2006). [The influence of a diet with including amaranth oil on antioxidant and immune status in patients with ischemic heart disease and hyperlipoproteidemia] [Article in Russian].Vopr Pitan 75 (6). 30-3.

9. Reinaudi, N.B., Repollo, R., Janovská, D., Délamo Frier, J., Martín de Troiani, R. (2009). Evaluación de genotipos de amaranto (Amaranthus spp.) para la adaptabilidad productiva en el área de la Facultad de Agronomía, Universidad Nacional de La Pampa, Argentina. The Scientific J. UDO agrícola, 11 (1): 50-57.

10. Troiani, R., Sánchez, T., Reinaudi, N. y Ferramola, L. (2004). Optimal sowing dates of three species of grain bearing amaranth in the semiarid Argentine Pampa. Span. J. Agric. Res., 2 (3), 385-391.

11. Harborne J.B. (1998). Phytochemical methods 3th ed, New York: Chapman and Hall Int., pp. 12.

12. Ramirez, M.R., Apel, M.A., Raseira, M.C.B., Zuanazzi, J.A.S., Henriques, A.T. (2011). Polyphenols content and evaluation of antichemotactic, antiedematogenic and antioxidant activities of Rubus sp. Cultivars. J Food Biochem., 35, 5:1389-1397.

13. American Asocciation of Blood Banks. (2012). Manual Técnico. (17 ed.). Maryland, USA: AABB.

14. U.K., Laemmli. (1970). Cleavage of structural proteins during the assembly of the head of bacteriophage T4. Naturc, 227 680-685.

15. Oyhenart, J., Martinez, F., Ramirez, R., Fort, M. and Breccia, J.D. (2013). Loop mediated isothermal amplification of 5.8 S rDNA for specific detection of Tritrichomonas foetus, Vet. parasitol., 193: 59-65.

16. Rogers, D.J. and Wend Loveless, R. (1991). Electron microscopy of human erythrocytes agglutinated by lectin from Codium fragile ssp. tomentosoides and pseudo-haemagglutinin from Ascophyllum nodosum. J. Appl. Phycol. 3:83. 